\title{
Broadening the absorption bandwidth of metamaterial absorber by coupling three dipole resonances
}

Vu, Dinh Qui; Le, Dinh Hai; Dinh, Hong Tiep; Trinh, Thi Giang; Yue, Liyang; Le, Dac Tuyen; Vu, Dinh Lam

\section{Physica B: Condensed Matter}

DOI:

10.1016/j.physb.2017.03.046

Published: 01/03/2018

Peer reviewed version

Cyswllt i'r cyhoeddiad / Link to publication

Dyfyniad o'r fersiwn a gyhoeddwyd / Citation for published version (APA):

Vu, D. Q., Le, D. H., Dinh, H. T., Trinh, T. G., Yue, L., Le, D. T., \& Vu, D. L. (2018). Broadening the absorption bandwidth of metamaterial absorber by coupling three dipole resonances. Physica B: Condensed Matter, 532, 90-94. https://doi.org/10.1016/j.physb.2017.03.046

\section{Hawliau Cyffredinol / General rights}

Copyright and moral rights for the publications made accessible in the public portal are retained by the authors and/or other copyright owners and it is a condition of accessing publications that users recognise and abide by the legal requirements associated with these rights. study or research.

- Users may download and print one copy of any publication from the public portal for the purpose of private

- You may not further distribute the material or use it for any profit-making activity or commercial gain

- You may freely distribute the URL identifying the publication in the public portal ?

Take down policy

If you believe that this document breaches copyright please contact us providing details, and we will remove access to the work immediately and investigate your claim. 
Broadening the absorption bandwidth of metamaterial absorber by coupling

three dipole resonances

Dinh Qui Vua, Dinh Hai Lea, Hong Tiep Dinha, Thi Giang Trinha, Liyang Yueb, Dac Tuyen Lea,c,?],

Dinh Lam Vua,d,?

\section{A B S T R A C T}

We numerically and experimentally investigated the metamaterial absorber (MMA) based on ring and dish structures in $\mathrm{GHz}$ region. It found that the combined structure of ring and dish (RD) exhibit dualband absorption peaks at 8.6 and $15.6 \mathrm{GHz}$. By replacing the ring to the structure of split-ring and dish (SRD), the first magnetic resonance peak is shifted from 8.6 to $14.0 \mathrm{GHz}$. The physical mechanism of magnetic resonance frequencies was elucidated using simple LC circuit model. We achieved a broadband MMA with bandwidth of $3.7 \mathrm{GHz}$ by arranging four SRD structures into a super unit-cell. The experimental results are good agreement with both the numerical simulation and calculation.

\section{Introduction}

Metamaterials (MMs) are well known as periodic arrangements of identical elements which have unique electromagnetic (EM) properties not available in nature [1]. The exotic properties of the MMs rely on the size, shape and geometry of the structures rather than their compositions. Therefore, the negative refractive index material [2], superlens [3] and invisibility cloak [4] have been obtained by properly designing the metamaterial structures. Besides investigating these exotic EM properties, a great number of devices, such as biological sensors [5], antenna [6] and perfect absorber [7] based on the MMs have been proposed.

Since the first experimental demonstration of Landy et al. in 2008 [8], MMAs have been a topic of major research interest due to a variety of possibilities for their realistic applications. However, most of the MMAs developed so far show a narrow absorption bandwidth. Many efforts including by optimizing multi-band have been made on the broadband MMA. Liu et al. used artificial dielectric "molecules" to create a dual-band MMA [9], Shen et al. used three square rings to create triple-band MMA [10], and Gong et al. found out a broadband MMA based on sectional asymmetric structures [11]. Nevertheless, these structures are still facing many difficulties about fabrication and measurement and not mention about explanation. Thus, to date, finding out a MMA not only simple in design, fabrication and measurement, but also high absorptivity and broadband are still in progress.

In this paper, the broadband MMA based on the conventional structures of ring and dish was investigated experimentally and numerically in $\mathrm{GHz}$ region. It found that the combined structure of ring and dish exhibit dual-band absorption peaks at 8.6 and $15.6 \mathrm{GHz}$. By replacing the ring to the SRD structure, the first absorption peak is shifted from 8.6 to $14.0 \mathrm{GHz}$. We developed a simple LC circuit model to calculate magnetic resonance frequencies, and the shift dependence of resonance peak was elucidated. The broadband absorption was achieved with the bandwidth of $3.7 \mathrm{GHz}$ when four SRD structures were arranged systematically in a super unit-cell. The experimental results were compared with both the simulated and calculated results. 
Fig. 1(a)-(c) illustrate the schematic geometry of the unit-cells of MMA of dish, ring and dish, and splitring and dish structures with the periodicity $a=10 \mathrm{~mm}$, respectively. The MMA structure consists of periodic metallic structure at the front and metallic plane at the back separated by dielectric substrate. The dielectric material is lossy-dielectric FR4 with thickness $t d=0.8 \mathrm{~mm}$, dielectric constant $\varepsilon=4.3$ and loss tangent of 0.025 . The metallic layers are copper with thickness $\mathrm{tm}=0.036 \mathrm{~mm}$ and conductivity of $5.8 \times 107 \mathrm{~S} / \mathrm{m}$.

Fig. 1.

Fig. 1. (a)-(c) Schematic geometry of the unit-cell of the dish, ring and dish, and split-ring and dish structures, respectively, with periodicity a $=10 \mathrm{~mm}$, thickness of copper layer $\mathrm{tm}=0.036 \mathrm{~mm}$, thickness of dielectric $t d=0.8 \mathrm{~mm}$, dielectric constant $\varepsilon=4.3$. $\mathrm{R}$ is the radius of the dish. Ro and Ri are the outer and inner radii of the ring. $g$ is the width of gap.

We performed the simulated calculations of the proposed MMAs using the commercial CST Microwave Studio with the finite-difference time domain (FDTD) [12]. Because the copper film at the back layer is thick enough to block all transmission, the absorption can be calculated as $A(\omega)=1$ $|S 11(\omega)| 2$ where $R(\omega)=|S 11(\omega)| 2$ is reflection. To optimize structural parameters, impedance matched to the free space, resulting in the reflection can be destructed $[8,13]$. To understand the absorption mechanism of the MMA, we also performed the surface current, electric field, and magnetic field distributions at the resonance frequencies. In addition, a simple LC circuit model was built to explain obtained results.

For the experiment, the dish, ring and dish, and split-ring and dish structures of were fabricated by using the conventional printed circuit board (PCB) with copper patterns $\mathrm{tm}=0.036 \mathrm{~mm}$ on both sides of dielectric substrate $t d=0.8 \mathrm{~mm}$ and dielectric constant $\varepsilon=4.3$. The geometrical parameters of the designed MMA are depicted in Fig. 1. The reflection measurements were performed by using a Hewlett-Packard E8362B network analyzer connected to the microwave standard-gain horn antennas. The EM wave was incident normal to the sample surface as shown in Fig. 1.

\section{Results and discussion}

The fabricated sample of RD structure and their absorption spectra are presented Fig. 2(a) and (b). Clearly, there exist two absorption peaks at 8.6 and $15.6 \mathrm{GHz}$. The experimental result agrees well with the simulation one. There is only slightly different between the experiment and simulation at the second peaks. It is caused by the error in the fabrication and measurement. In order to confirm the cause of their absorption peaks, we simulated surface current distributions at 8.6 and $15.6 \mathrm{GHz}$ as shown in Fig. 2(c) and (d). The result shows that the currents at the front and back layers are antiparallel. It confirmed that the absorption peaks are due to magnetic resonance $[8,14]$. The surface currents of the first and second peaks are mostly focused at the ring and dish positions, respectively. It indicates that the first absorption peak is due to the dish, and the second peak is due to the ring. In addition, the magnetic-coupling effect between the ring and dish in combined structure might be contributed. However, the difference is in the range of tolerance and reasonable. Actually, the 
absorption frequencies of each individual ring or dish structures which were investigated in our previous reports $[15,16]$.

Fig. 2.

Fig. 2. (a) The fabricated RD structure, (b) Comparison of the measured and simulated absorption spectra of the RD structure, (c) and (d) The surface current distributions on the top copper layer at the two absorption peaks, respectively.

In order to confirm the above results, we have built the LC circuit model for those structures. The effective capacitance of the ring or dish structure is specified as formula:

where $\mathrm{c} 1$ is the numerical factor calculated as the ratio of the charge distribution area to the ring or dish area. The effective inductance of the ring or dish structure is determined as equation by applying the Faraday's law of magnetic flux ( and the Ampere's law of the magnetic field density (B):

where $\mathrm{N}$ is the number of magnetic flux loop, for these structure, $\mathrm{N}=1 ; \mathrm{S}$ is the cross-section area magnetic field $B$ through. The magnetic resonance frequency is calculated:

(3)

Thence, the absorption peak frequencies of the dish and ring structures are estimated respectively as:

where $c, \mu$ and $\varepsilon$ are the speed of light in vacuum, the permeability of copper, and the permittivity of the dielectric, respectively. The geometrical factor $\mathrm{c} 1$ is in the range from 0.05 to 0.3 [14]. The values of $c 1$ in dish structure (Eq. (4)) and ring structure (Eq. (5)) are different that depends on the value of S0. By using these formula, the resonant frequencies are calculated $\mathrm{fr}=8.8 \mathrm{GHz}$ with $\mathrm{c} 1=0.15$ and $\mathrm{fd}=15.6 \mathrm{GHz}$ with $\mathrm{c} 1=0.20$ corresponding to individual ring and dish structures, respectively. These results are good agreement with the experimental and simulated results.

In effort to extend absorption bandwidth of MMA, a gap g was created in the ring, and the RD structure becomes to the SRD structure. Fig. 3(a) displays a photo of the fabricated SRD structure with gap $g=0.3$ $\mathrm{mm}$ when periodicity and other structural parameters are kept to be constant. Fig. 3(b) presents the measured and simulated absorption spectra of the SRD structure. Again, a good agreement between experiment and simulation is obtained. From the comparison of the absorption peaks between the RD and SRD structures, it clearly displays that the first absorption peak at $8.6 \mathrm{GHz}$ is shifted to $14.0 \mathrm{GHz}$ while the second one at $16.2 \mathrm{GHz}$ is small shifted. It indicates that the gap in SRD structure is played an important role to shift the first absorption peak. The obtained result is similar to the Zhang's work on three dipole resonances [17]. Nevertheless, Zhang et al. did not explain the cause leads to shift the 
resonance frequency. Here, we use the LC circuit model to clarify the physical mechanism and explain how to tune the absorption peak by SR structure. To specify the position of electric dipolar, Fig. 3(c) and (d) illustrate the electric field and magnetic field distributions of the SRD structure at $14.0 \mathrm{GHz}$, respectively. It indicates that the charge is focused at 4 areas instead of 2 areas as in the ring structure. When the ring is cut in the position where the magnetic field focuses, the induced current is separated into two halves that lead to redistribute charges and create three electric and magnetic dipoles.

Fig. 3.

Fig. 3. (a) The fabricated SRD structure; (b) Comparison of the simulated and measured absorption spectra of the RD structure; (c) and (d) The electric field and magnetic field distributions on front copper layer at the first resonance frequency.

Based on the electric field and magnetic field distributions, we built the equivalent LC circuit of SR structure. Fig. 4(a) shows the LC circuit model of SR structure. The solid and dashed lines are the inductors and capacitors in the top and bottom layers, respectively. The arrows display the direction of antiparallel induced currents. Because the opposite polarity charge caused by the split gap, a capacitance $\mathrm{Ce}$ is found, and the value of capacitance $\mathrm{Ce}$ is estimated as:

(6)

Fig. 4.

Fig. 4. (a) The LC circuit model and (b) The effective LC circuit model of SR structure.

However, the value of capacitance $\mathrm{Ce}$ is too small and can be ignored. For simplifying in the calculation, we can use effective LC circuit model of SR structure corresponding to a dipolar resonance as shown in Fig. 4(b). In which, the value of effective inductance $\mathrm{Lm}$ approximates one-third of the inductance of the ring structure. From the Eq. (2), the value of $\mathrm{Lm}$ is calculated by formula:

(7)

Through Eq. (1), the value of effective capacitance $\mathrm{Cm}$ is worked out as:

(8)

Thence, the resonance frequency is estimated as equation:

(9)

Similar $\mathrm{c} 1$, the value $\mathrm{c} 2$ is the ratio of the charge distribution area and the ring area which also depends on the width of the gap. By using the formula (9), the resonant frequency of the RS structure is 
calculated with the values of $13 \mathrm{GHz}$ that agrees with simulated result when $\mathrm{c} 2=0.096$. This value is agreement with simulated and experimental results.

Fig. 5(a) and (b) illustrate the dependence of the absorption spectra on the gap of SRD structure in both the simulation and experiment cases. The width of the gap is varied from 0.2 to $1.4 \mathrm{~mm}$. We clearly see that the higher resonance frequencies are slightly change while the lower resonance frequencies are greatly shifted as the various values of gap. The experimental result is quite coincident with simulated result. The shift of the absorption peak to higher frequency is explained through the reduction of effective inductor length value. When the gap is widened, the value of the effective length of one-third of the ring is reduced, resulting in the decrease of the effective inductor value. The difference in absorption bandwidth and absorption peak has discussed above.

Fig. 5.

Fig. 5. Dependence of the simulated (a) and measured (b) absorption spectra on the width of gap.

By arranging four unit-cells of the SRD structure with different sizes into a super cell, we can increase the absorption bandwidth of SRD structure. Fig. 6(a) and (b) show the fabricated and designed MMA, respectively. The thickness of the metal plane and the dielectric layer are kept to be constant. The periodicity of super unit-cell is a $=15 \mathrm{~mm}$. The radius of the dish, the outer and inner radii of the ring, and the width of the gap of the super cell are $R 1=2.20, R o 1=3.10$, Ri1 $=2.80$, and g1 $=0.70 \mathrm{~mm} ; \mathrm{R} 2=2.45$, $\mathrm{Ro} 2=3.40$, Ri2=3.10, and $\mathrm{g} 2=0.60 \mathrm{~mm}$; R3=2.30, Ro3=3.20, Ri3=2.90, and $\mathrm{g} 3=0.70 \mathrm{~mm}$; R4=2.10, Ro4=30, Ri4=2.70, and g4=1.25 mm, respectively.

Fig. 6

Fig. 6. (a) and (b) The fabricated and designed super unit-cell of SRD structure. (c) and (d) The eight absorption peaks and located magnetic field distribution; (e) Comparison of absorption spectra of measurement (dotted line) and simulation (solid line) of optimized SRD structure.

As mention above, a SRD structure exhibits dual-band absorption peaks. Therefore, the super unit-cell of SRD structure can create four dual-bands or eight absorption peaks operating at $f 1=12.3, f 2=13.1$, $f 3=13.8, f 4=14.7, f 5=15.2, f 6=16.0, f 7=17.0, f 8=17.8 \mathrm{GHz}$ as shown in Fig. $6(\mathrm{c})$. Fig. 6 (d) displays the magnetic field distribution at resonance frequencies. It indicates each resonance peak is created by a SRD structure. The obtained results suggest that we can optimize parameters to get broadband MMA. Fig. 6(e) shows the comparison of experimental results (dotted line) versus simulation (solid line). A good agreement between measurement and simulation was observed. When the values including the radius of the dish, the outer and inner radii of the ring in millimeter after adjustment are $R 1=2.45$, Ri1=2.95, Ro1=3.15; R2=2.60, Ri2=3.35, Ro2=3.50; R3=2.55, Ri3=2.90, Ro3=3.25; R4=2.40; Ri4=2.8, Ro4=3.10, the broadband MMA is achieved with bandwidth of $3.7 \mathrm{GHz}$ (the relative bandwidth is about $26 \%$ ) and absorption higher than $80 \%$. 


\section{Conclusion}

We have investigated experimentally and numerically the broadband $\mathrm{MMA}$ operating at $\mathrm{GHz}$ frequency. The dual-band magnetic resonances were achieved with the combined structure consist of ring and dish, and the first resonance frequency can be controlled by replacing the ring to the splitring. Direct derivation of resonance frequencies was explained and confirmed using the simple LC model. The experimental results are good agreement with the simulation and calculation. A design super unit-cell to achieve broadband MMA is proposed by employing four SRD structures with bandwidth of $3.7 \mathrm{GHz}$ and absorption higher than $80 \%$.

\section{Acknowledgement}

This research was funded by the Vietnam National Foundation for Science and Technology Development (NAFOSTED) under grant number 103.02-2015.84.

\section{References}

[1]

\section{V.G. Veselago}

Sov. Phys. Usp., 105 (1968), p. 509

CrossRefView Record in Scopus

[2]

D.R. Smith, W.J. Padilla, D.C. Vier, S.C. Nemat-Naser, S. Shultz

Phys. Rev. Lett., 84 (2000), p. 4184

CrossRefView Record in Scopus

[3]

N. Fang, H. Lee, C. Sun, X. Zhang

Science, 308 (2005), p. 534

CrossRefView Record in Scopus

[4]

D. Schurig, J.J. Mock, B.J. Justice, S.A. Cummer, J.B. Pendry, A.F. Starr, D.R. Smith

Science, 314 (2006), p. 977

CrossRefView Record in Scopus

[5]

B.S. Tung, D.D. Thang, H.D. Luu, V.D. Lam, O. Akihiko, T. Nabatame, Y.P. Lee, T. Nagao, V.H. Chung Sci. Rep., 6 (2016), p. 32123 
View Record in Scopus

[6]

P.T. Bowen, A. Baron, D.R. Smith

Phys. Rev. A, 93 (2016), p. 63849

[7]

M. Lei, N. Feng, Q. Wang, Y. Hao, S. Huang, K. Bi

J. Appl. Phys., 119 (2016), p. 244504

CrossRef

[8]

N.I. Landy, S. Sajuyigbe, J.J. Mock, D.R. Smith, W.J. Padilla

Phys. Rev. Lett., 100 (2008), p. 207402

CrossRef

[9]

X. Liu, C. Lan, B. Li, Q. Zhao, J. Zhou

Sci. Rep., 6 (2016), p. 28906

[10]

X. Shen, Y. Yang, Y. Zang, J. Gu, J. Han, W. Zhang, T.J. Cui

Appl. Phys. Lett., 101 (2012), p. 154102

CrossRef

[11]

C. Gong, M. Zhan, J. Yang, Z. Wang, H. Liu, Y. Zhao, W. Liu

Sci. Rep., 6 (2016), p. 32466

[12]

CST Computer Simulation Technology 3D EM Field Simulation. 〈http://www.cst.com/〉 .

[13]

N. Mattiucci, M.J. Bloemer, N. Akozbek, G. D’Aguanno

Sci. Rep., 3 (2013), p. 3203

View Record in Scopus

[14]

J. Zhou, E.N. Economon, T. Koschny, C.M. Soukoulis

Opt. Lett., 31 (2006), p. 3620 
CrossRefView Record in Scopus

[15]

D.T. Viet, N.T. Hien, P.V. Tuong, N.Q. Minh, P.T. Trang, L.N. Le, Y.P. Lee, V.D. Lam

Opt. Commun., 322 (2014), p. 209

ArticleDownload PDFView Record in Scopus

[16]

T.H. Nguyen, S.T. Bui, T.T. Nguyen, T.T. Nguyen, Y.P. Lee, M.A. Nguyen, D.L. Vu

Adv. Nat. Sci.: Nanosci. Nanotechnol., 5 (2014), p. 025013

[17]

J. Zhang, G. Wang, B. Zhang, T. He, Y. He, J. Shen

Opt. Mater., 54 (2016), p. 32

ArticleDownload PDFCrossRefView Record in Scopus 